\title{
Stress, Autonomic Reactivity and Blood Pressure among Undergraduate Medical Students
}

\author{
Khaliq F, ${ }^{1}$ Gupta K, ${ }^{2}$ Singh $P^{2}$ \\ 'Department of Physiology, University College of Medical Sciences, ${ }^{2}$ Medical Student, University College of Medical Sciences, \\ Delhi, India.
}

\section{ABSTRACT}

Introduction: Medical training is highly stressful particularly for those who are beginning their medical education. The present study was undertaken to find out the level of stress, hypertension and its etiological factors among undergraduate medical students.

Method: One hundred and seventeen undergraduate medical students between 17-21 years of age got examined for blood pressure and stress level. Twelve hypertensives selected from the above subjects and twenty normotensives underwent cold pressure test to assess autonomic reactivity to laboratory induced stress.

Results: $10.25 \%$ of the subjects were found to be hypertensive and $6.83 \%$ pre hypertensive. On the stress scale $53 \%$ had mild stress, $7 \%$ showed moderate stress while none had stress as a major problem. There was no correlation between BP and stress score. On CPT, BP increased significantly in both the hypertensive and normotensive group but came back to basal levels within 5 minutes indicating normal autonomic response. Rise of BP was higher in hypertensive group. The diastolic and mean BP increased significantly on CPT in subjects having family history of hypertension. The subjects taking more of junk and oily foods had a higher systolic BP. Forty percent of normotensive subjects had more than $20 \mathrm{~mm} \mathrm{Hg}$ rise in systolic BP on CPT.

Conclusions: Adolescents must be routinely screened to detect asymptomatic hypertension. Advice on risk factor modification by appropriate lifestyle changes may prevent long term effects of hypertension on target organs.

Key Words: autonomic reactivity, blood pressure, cold pressor test, medical students, stress

\author{
Correspondence: \\ Dr Farah Khaliq \\ Department of Physiology \\ University College of Medical Sciences and GTB Hospital, \\ Dilshad Garden, Delhi, India. \\ E mail: farahphysio@yahoo.com \\ Phone: 9868350022
}




\section{INTRODUCTION}

Hypertension is a very common abnormality in humans specially in the modern world which is full of stress, worries and anxieties. ${ }^{1}$ Several studies both from west ${ }^{2-}$ ${ }^{4}$ and from Asia $^{5}$ have reported that medical training is highly stressful particularly for those who are beginning their medical education. Also previous studies have shown that repeated pressor episodes may lead to sustained hypertension and hypertensive patients recover very slowly than normotensives after laboratory induced stress. ${ }^{6}$

Over activity of sympathetic nervous system also plays an important role in pathogenesis of neurogenic hypertension in young individuals. ${ }^{7}$ The subject, whose cardiovascular system, is very sensitive to a stressor and recovers slowly after its withdrawal, is at high risk of developing hypertension in future. ${ }^{6}$

Early diagnosis is essential to minimize the cardiovascular risk and damage to other target organs. The diagnosed patient can live a healthy life by altering his lifestyle and diet.

\section{METHODS}

The present cross sectional study was conducted in August and September 2008. One hundred and seventeen undergraduate medical students of first and second year from University College of Medical Sciences, Delhi volunteered for this study. They belonged to the age group of 17-21 years. Subjects with history of any chronic illness or drug intake known to influence blood pressure were excluded from the study. Informed written consent was taken from the subjects and institutes ethical committee approved the study.

Each student filled up a questionnaire recording his/her age, sex, address, dietary habits, lifestyle, family history of illness etc. Anthropometric parameters like height and weight of the subjects were measured to calculate their BMI. Height was measured by stadiometer to nearest 1 $\mathrm{cm}$ with subject standing without shoes and weight by weighing scale to the nearest $1 \mathrm{~kg}$. A professional life stress proforma was also filled by the students. ${ }^{8}$ The stress proforma had questions regarding stress because of their academics, peer pressure, the relationship they share with their teachers, time for personal needs etc.

The blood pressure of all the subjects was measured in the right arm by auscultatory method using standard mercury sphygmomanometer in sitting position. Before measuring blood pressure the subjects were made to rest for ten minutes to allay anxiety. The $1^{\text {st }}$ and the $5^{\text {th }}$ Korotkoff sounds were indicative of the systolic and the diastolic blood pressure. Subjects found to be hypertensive during first recording were checked for their blood pressure three times at weekly intervals. Students with systolic blood pressure $3130 \mathrm{mmHg}$ or diastolic blood pressure $385 \mathrm{mmHg}$ for all the above three readings were considered as pre hypertensive. While those having systolic $>$ $140 \mathrm{mmHg}$ or diastolic $>90 \mathrm{mmHg}$ were considered as hypertensive. $^{9}$

In the second phase of examination, Cold pressure test (CPT) was performed on twelve subjects diagnosed as hypertensives from the above subjects. Twenty randomly selected normotensive subjects also underwent CPT. Before the cold pressor test a baseline blood pressure was recorded by tying the cuff on the right arm. Then the subject was directed to dip his left hand up to his wrist in a water kettle having water at four degrees Celsius for five minutes. If the subject was not able to bear cold water the hand was taken out. The second recording of blood pressure was taken during the CPT. The hand was than wrapped in a towel for five minutes and the third reading of BP was taken after this. Before performing CPT the procedure was explained to the subjects. The same person took all the measurements. The instruments were calibrated on the day of the examination.

Statistical analysis was performed using SPSS 13.0 version. Inter and intra group comparisons were done by repeated measure ANOVA with Tukey test at $5 \%$ level of significance. Pearson correlation at $5 \%$ level of significance was used to find the correlation between $\mathrm{BP}$ and stress score.

\section{RESULTS}

Of all the hundred and seventeen subjects studied $10.25 \%$ were found to be hypertensive while $6.83 \%$ were pre hypertensive. On the stress scale $53 \%$ subjects had mild stress, $7 \%$ had moderate stress and none had stress as a major problem. There was no correlation between BP and stress score. The comparison between subjects and controls is shown in Table 1. There is no difference between the two groups in age, height, weight BMI and stress score. The BP is significantly different between the two groups.

Table 1. Comparison between normotensive and hypertensive subjects on the basis of anthropometric parameters and stress score

\begin{tabular}{lll}
\hline Parameter & Normotensive & Hypertensive \\
\hline & $(\mathrm{n}=20)$ & $(\mathrm{n}=12)$ \\
Age $(\mathrm{yrs})$ & $18.70 \pm 1.17$ & $18.20 \pm 1.28$ \\
Height $(\mathrm{cms})$ & $174.28 \pm 7.01$ & $173.60 \pm 5.40$ \\
Weight $(\mathrm{kg})$ & $66.85 \pm 11.44$ & $69.45 \pm 10.87$ \\
BMI & $21.93 \pm 3.10$ & $23.07 \pm 3.40$ \\
Stress Score & $17.00 \pm 8.05$ & $20.30 \pm 4.99$ \\
Mean BP $(\mathrm{mm} \mathrm{Hg})$ & $90.9 \pm 5$ & $104.6 \pm 7.5^{*}$ \\
\hline$* \mathrm{P}<0.05$ & &
\end{tabular}


The BP variation with CPT is shown in Table 2. The systolic, diastolic and mean BP increased significantly after the CPT but came back to baseline values within five minutes. These changes were observed in both the groups. Forty percent of normotensive subjects had more than $20 \mathrm{~mm} \mathrm{Hg}$ rise in systolic BP.

Table 2. Blood pressure varition with the Cold pressure test in normotensive \& hypertensive subjects

\begin{tabular}{llll}
\hline Parameter & Readings & Normotensive $(\mathrm{n}=20)$ & Hypertensive $(\mathrm{n}=12)$ \\
\hline & 1st & $117.60 \pm 7.06$ & $135.30 \pm 14.75^{*}$ \\
Systolic BP & 2nd & $134.10 \pm 12.13$ & $147.50 \pm 14.92^{*}$ \\
$(\mathrm{mmHg})$ & 3rd & $115.50 \pm 7.59$ & $132.8 \pm 12.82^{*}$ \\
& 1st & $77.60 \pm 5.78$ & $89.20 \pm 7.60^{*}$ \\
Diastolic BP & 2nd & $93.70 \pm 10.64$ & $94.20 \pm 14.33$ \\
$(\mathrm{mmHg})$ & 3rd & $81.00 \pm 5.78$ & $87.20 \pm 7.55$ \\
& 1st & $90.9 \pm 5.0$ & $104.6 \pm 7.5^{*}$ \\
Mean BP & 2nd & $107.2 \pm 10.3$ & $112 \pm 11.4$ \\
$(\mathrm{mmHg})$ & 3rd & $92.5 \pm 4.8$ & $102.4 \pm 7.2^{*}$ \\
\hline
\end{tabular}

${ }^{*} \mathrm{P}<0.05$

$1^{\text {st }}$ Reading - Base line blood pressure

$2^{\text {nd }}$ Reading - Immediately after cold pressor test

$3^{\text {rd }}$ Reading - five minutes after cold pressor test

Intra group significance is also observed in all the three systolic, diastolic and mean BP in both the groups.

The comparison of the subjects on the basis of diet is shown in Table 3. The subjects taking junk food more than twice per week, more of oily food and less fruits had a higher systolic BP. Diastolic and mean BP were not significantly different in the two groups. There was no difference observed in the BP on the basis of life style.

Table 3. BP changes with respect to diet

\begin{tabular}{lll}
\hline & $\begin{array}{l}\text { Group 1 } \\
\text { (Subjects taking } \\
\text { more junk food) }\end{array}$ & $\begin{array}{l}\text { Group 1 } \\
\text { (Subjects taking } \\
\text { more fruits) }\end{array}$ \\
\hline Systolic $\mathrm{BP}(\mathrm{mmHg})$ & $131.78 \pm 16.39 *$ & $122.09 \pm 11.38$ \\
Diastolic BP $(\mathrm{mmHg})$ & $85.44 \pm 9.27$ & $81.73 \pm 8.40$ \\
Mean BP $(\mathrm{mmHg})$ & $101 \pm 10$ & $95 \pm 8$ \\
\hline
\end{tabular}

* $P<0.05$

Taking into consideration the family history of hypertension, there was a significant rise in diastolic and mean BP during CPT in these subjects. The baseline values of BP were not different in the two groups (Table 4 ). Family history of hypertension was present in $46.66 \%$ of hypertensives, $40 \%$ of pre hypertensives as against $35 \%$ of normotensives.

Table 4. BP changes with respect to family history of hypertension

\begin{tabular}{|c|c|c|c|}
\hline Parameter & & $\begin{array}{l}\text { Family history } \\
\text { present }\end{array}$ & $\begin{array}{l}\text { Family history } \\
\text { absent }\end{array}$ \\
\hline \multirow{3}{*}{$\begin{array}{l}\text { Systolic } \\
(\mathrm{mmHg})\end{array}$} & $1 \mathrm{st}$ & $128.12 \pm 16.17$ & $125.22 \pm 13.39$ \\
\hline & 2nd & $144.47 \pm 17.09$ & $138.09 \pm 13.05$ \\
\hline & $3 r d$ & $125.53 \pm 15.35$ & $123.13 \pm 12.40$ \\
\hline \multirow{3}{*}{$\begin{array}{l}\text { Diastolic BP } \\
(\mathrm{mmHg})\end{array}$} & $1 \mathrm{st}$ & $86 \pm 10.63$ & $81.48 \pm 6.98$ \\
\hline & 2nd & $99.88 \pm 11.21$ & $89.57 \pm 11.69 *$ \\
\hline & $3 r d$ & $85.76 \pm 8.42$ & $82.87 \pm 6.34$ \\
\hline \multirow{3}{*}{$\begin{array}{l}\text { Mean } \\
(\mathrm{mmHg})\end{array}$} & $1 \mathrm{st}$ & $100 \pm 12$ & $96 \pm 7$ \\
\hline & 2nd & $115 \pm 13$ & $106 \pm 8^{*}$ \\
\hline & $3 r d$ & $99 \pm 10$ & $96 \pm 6$ \\
\hline
\end{tabular}

\footnotetext{
* $\mathrm{P}<0.05$

$1^{\text {st }}$ Reading - Base line blood pressure

$2^{\text {nd }}$ Reading - Immediately after cold pressor test

$3^{\text {rd }}$ Reading - five minutes after cold pressor test
}

\section{DISCUSSION}

Prevalence of hypertension according to JNC criterion ${ }^{9}$ was observed to be $10.25 \%$ and that of pre hypertension 
$6.83 \%$. Out of which two students were aware of their hypertensive status while the rest were not. Other studies of blood pressure of adolescents in our country have reported $0.46 \%$ to $11.9 \%$ prevalence. ${ }^{10-3}$ This wide difference may be due to different standards used for the diagnosis of hypertension and also due to regional variation. Some studies have adopted fourth phase of Korotkoff sound to define the diastolic blood pressure. ${ }^{14}$ There is higher incidence of hypertension in Southern India ${ }^{15}$ probably because of influencing factors, genetic inheritance, dietary habits and lifestyle factors. The difference in ethnicity may also be one of the factors.

Higher prevalence of hypertension in the present study could be due to majority of students belonging to middle or upper middle socioeconomic status. The changing diet and lifestyle are contributing to the rise in blood pressure. More over the present study is done on medical students who are under stress due to academic demands and are having more sedentary lifestyle as compared to general population. This may be contributing to higher incidence of blood pressure in them.

In the present study $53 \%$ subjects had moderate stress on the stress scale and in $7 \%$ stress was clearly a problem. This is in agreement with previous reports where academic demands of medical training during the first year are a significant source of stress. ${ }^{2,3,5}$ The increased level of stress in our subjects did not have a significant correlation with hypertension.

Autonomic reactivity to stress has been hypothesized to be a marker for subsequent neurogenic hypertension. Cold pressor test assesses the discriminative or prognostic value of excessive reactivity to a standardized cold stimulus. It is observed that hypertensive persons show greater lability of BP under various forms of stress than do normotensive persons. ${ }^{16}$ The normotensive hyper reactors to CPT are more likely to have a positive family history of hypertension than normotensive persons who are less reactive. ${ }^{17,18}$ The hyper reactors to CPT with slower rate of recovery may be predisposed to the development of essential hypertension at a later point of time. ${ }^{19}$ In the present study all the subjects had complete recovery within five minutes indicating that their autonomic control system is competent enough to bring down the BP to baseline. Since $40 \%$ of normotensive subjects in our study had more than $20 \mathrm{mmHg}$ rise in systolic BP on CPT, they are more prone to develop hypertension in future and were advised to modulate their lifestyle.

In the present study systolic BP was higher in the subjects who took more of junk and oily foods and less of fruits.
Similar results were obtained earlier. ${ }^{13}$ It is generally accepted that hypertensive individuals benefit from a dietary increase in fresh vegetables, fruits, fibers and reduction of sodium. ${ }^{9,13}$ Lower BP has been associated in children and adolescents with an increase intake of potassium, magnesium, folic acid and fiber which are rich in vegetables and fruits. ${ }^{9}$

We studied the subjects on the basis of lifestyle but could not get any significant difference. This may be because most of our subjects had a sedentary lifestyle and even though a few were in a practice of doing exercise, it was of very mild category. Since most of our subjects were unaware of their hypertensive status, they were advised to modulate their diet and lifestyle. One of the subjects diagnosed as hypertensive on further investigation was found to be having left ventricular hypertrophy and is on antihypertensive drugs now.

Family history of hypertension was present in $45 \%$ of hypertensives as against $35 \%$ of normotensives. The baseline values of BP were not significantly different in the two groups. The diastolic and mean BP increased significantly on Cold pressor test in subjects having family history of hypertension but came back to baseline values within five minutes. Family history of hypertension is a well established risk factor.20,21

Young subjects who show greater and prolonged responsiveness to diastolic BP due to sympathetic stimulation through CPT are reported to be more prone to develop hypertension. ${ }^{6}$ Once stimulated by a stressor, sympathetic system causes rise in heart rate and BP but usually these parameters return to normal level within five minutes after withdrawal of the stressor. The persons, who show higher cardiovascular reactivity to a stressor and slower rate of recovery after the withdrawal of stressor that caused sympathetic stimulation, indicate that their autonomic control system is not competent enough to bring down the BP to baseline quickly. None of our subjects showed incompetent autonomic response.

\section{CONCLUSIONS}

The prevalence of hypertension in our study was $10.25 \%$, pre hypertension $6.83 \%$ while that of mild stress $53 \%$ and moderate stress $7 \%$. There was no correlation observed between the two parameters. Diet has a positive influence on systolic BP, while family history of BP and life style did not have a significant effect. Forty percent of normotensive subjects are more prone to develop hypertension in future. 


\section{REFERENCES}

1. Ganong WF. Review of Medical Physiology. 22nd ed. USA: Appleton and Lange; 2005.

2. Miller PM. The first year at medical school: some findings and student perceptions. Med Educ J. 1994;28:5-7.

3. Vitaliano PP, Russo J, Carr JE, Heerwagen JH. Medical school pressures and their relationship to anxiety. J Nerv Ment Dis. 1984;172:730- 6 .

4. Stewart SM, Betson C, Marshall I, Wong CM, Lee PWH, Lam TH. Stress and vulnerability in medical students. Med Educ. 1995;29:119-27.

5. Srinivasan K, Vaz Mario, Sucharita S. A study of stress and autonomic nervous function in first year undergraduate medical students. Indian J Physiol Pharmacol. 2006;50(3):257-64.

6. Pramanik T, Regmi P, Shrestha P. Detection of individuals prone to develop hypertension in their future life. Nepal Med Coll J. 2008;10(1):35-7.

7. Schneider GM, Jacobs DW, Gevirtz RN, O'Connor DT. Cardiovascular haemodynamic response to repeated mental stress in normotensive subjects at gentic risk of hypertension: evidence of enhanced reactivity, blunted adaptation and delayed recovery. J Human Hypertens. 2003;17:829-40.

8. Fontana D. Professional life stress scale. In: Managing Stress. London: The British Psychological Society and Routledge Ltd; 1989.

9. The fourth report on the Diagnosis, Evaluation and Treatment of High blood pressure in children and adolescents. National High Blood Pressure Education program working group on high blood pressure in Children and Adolescents. Pediatrics. 2004;114:555-76.

10. Chhabra P, Grover VL, Aggarwal K, Kannan AT. Nutritional Status and Blood Pressure of Medical Students in Delhi. Indian J Community Medicine. 2006;31(4):248-51.
11. Gupta R, Goyle A, Kashyap S, Agarwal M, Consul R, Jain B. Prevalence of arthrosclerosis risk factors in adolescent school children. Indian Heart J. 1998;50:511-5.

12. Gopinath N, Chadha SL, Sood AK, Shekhawat S, Bindra SPS, Tandon R. An epidemiology study of blood pressure in school children (5-14 years) in Delhi. Indian J Med Res. 1994;99:32-7.

13. Savitha MR, Krishnamurthy B, Fattehpur S, Shayana R, Yashwanth K, Khan MA. Essential hypertension in Early and Mid- adolescence. Indian Pediatrics. 2007;74(11):1007-11.

14. Anand NK, Tandon L. Prevalence of hypertension in school going children. Indian Pediatrics. 1996;33:337-81.

15. Guptha R. Meta analysis of hypertension in India. Indian Heart J. 1997;49:43-8.

16. Levy RL, Hillman CC, Stroud WD, White PD. Transient hypertension: Its significance in terms of later development in sustained hypertension and cardiovascular-renal disease. JAMA. 1944;126:829-33

17. Wood DL, Sheps SG, Eleback LR, Schirger A. Cold pressor test as a predictor of hypertension. Hypertension. 1984;6:301-6.

18. Briggs JF, Oerting H. Vasomotor response of normal and hypertensive individuals to thermal stimulus (cold). Minn Med. 1981;16:481-6.

19. Mathews KA, Woodall KL, Allen MT. Cardiovascular reactivity to stress predicts future blood pressure status. Hypertension. 1993;22:479-85.

20. Guptha AK. Influence of family history of morbid cardiovascular events on blood pressure levels of school children. Indian Pediatrics. 1991;28:647-53.

21. Chadha SL, Tandon R, Shekhawat S, Gopinath N. An epidemiology study of blood pressure in school children (5-14 years) in Delhi. Indian Heart J. 1999;51:178-82. 